\title{
Vision-based Fuzzy Proportional-Integral-Derivative Tracking Control Scheme for Gantry Crane System
}

\author{
Feijie Zheng, Chi-Hsin Yang, ${ }^{*}$ Gao Hao, Kun-Chieh Wang, and Hai-Lian Hong \\ School of Mechanical and Electric Engineering, Sanming University, Sanming 365004, Fujian Province, China
}

(Received March 29, 2021; accepted June 30, 2021)

Keywords: gantry crane system, fuzzy PID, trajectory tracking, anti-swing

A vision-based fuzzy proportional-integral-derivative (PID) control scheme for a twodegree-of-freedom (2DOF) gantry crane system is introduced in this paper. By applying the experimental prototype of a 2DOF gantry crane system, a two-inputs-three-outputs variable universe fuzzy adaptive PID (VUFAPID) control scheme is proposed for controlling the position of the trolley and the length of the cable. This control scheme combines the variable universe method and fuzzy adaptive PID (FAPID) control. The designed control scheme is applied to control the motion of the crane tip and to compensate for load oscillations to achieve the desired effects of trajectory tracking and limiting the swing. Experimental results demonstrate the effectiveness of the proposed scheme.

\section{Introduction}

Gantry crane systems have been widely used in container lifting, ship equipment transportation, hydropower stations, thermal power plants, and other industrial operations. ${ }^{(1)}$ Because of their wide operating range and the ability to lift heavy loads, gantry crane systems are usually applied to improve the efficiency of work, reduce physical labor, and ensure safety in production. (2) However, the safety and operational efficiency of a gantry crane system are affected by the hoisting of loads and the swing of the cable under external interferences. ${ }^{(3)}$ Gantry crane systems often rely on experienced operators to position the crane and perform antiswing measures. Because of the burden on operators, it is difficult to always ensure accurate operation and safety. ${ }^{(4)}$

To improve the performance of gantry crane systems, an appropriate control system design is usually applied. Many control methods have been successfully utilized in gantry crane control systems, such as proportional-integral-derivative (PID) control, ${ }^{(5)}$ fuzzy control, ${ }^{(6)}$ geneticalgorithm-based linear-quadratic regulator (LQR), ${ }^{(7)}$ model reference adaptive control, ${ }^{(8)}$ nonlinear feedback control, ${ }^{(9)}$ passivity-based control, ${ }^{(10)}$ robust adaptive control, ${ }^{(11)}$ sliding mode control, ${ }^{(12,13)}$ neural network PID control, ${ }^{(14)}$ and vision-based control. ${ }^{(5,6,9,15,16)}$ Because of the simple structure and the convenience of adjustment, PID control was the first practical controller to be developed and is still widely used. Fuzzy control theory was first proposed by Zadeh in $1965^{(17)}$ and has been employed in many practical applications. The advantage of a

*Corresponding author: e-mail: 20190207@fjsmu.edu.cn https://doi.org/10.18494/SAM.2021.3403 
fuzzy control scheme is that the controlled system is handled by a similar type of decisionmaking to that of humans owing to the elimination of detailed mathematical models. ${ }^{(18,19)}$ Moreover, by adding an extra layer of intelligence, a fuzzy control scheme can be combined with PID control to realize more useful and practical control schemes, such as fuzzy adaptive PID (FAPID) control ${ }^{(20)}$ and variable universe fuzzy adaptive PID (VUFAPID) ${ }^{(21-24)}$ control.

Regarding the control of gantry crane systems in the literature, in Ref. 25, an intelligent control scheme combined with root locus and frequency domain methods was proposed for positioning and anti-swing control. Double closed-loop controllers were also developed by the same research team, ${ }^{(26)}$ where the inner loop was used for fuzzy anti-swing control and the outer loop was used to control the position of the trolley by a PI controller. In Ref. 27, an input-shaping scheme integrated with a distributed delay to control a gantry crane was proposed. In Refs. 14 and 28, a type of neural network PID control and time-delayed fuzzy logic feedback control were introduced to control the position and swing motion, respectively. A hierarchical fast terminal sliding mode control method applying sliding mode technology was proposed in Ref. 12, and in Ref. 13, an adaptive neuro-sliding mode for anti-swing stabilization by controlling the length of cable was proposed.

Vision-based control has recently attracted significant attention for use in mechatronics. Geometrical information from the environment surrounding the controlled gantry crane system can be obtained by machine vision and used for motion planning and control. In Ref. 5, PID control was integrated with computer vision, which was employed to measure the swing angle of the load. In Ref. 6, a vision system was applied to detect the position of a gantry crane trolley as it moved. Then, fuzzy control was utilized to address the nonlinearity provided by both the vision and an angle sensor. In Ref. 16, the use of vision-based control to extract both the trolley position and the load swing information for the effective tracking control of the gantry crane was demonstrated. In Ref. 9, the coordinates of the start and end positions of a load were found by image recognition based on machine vision positioning using a quick response (QR) code. Then, a developed nonlinear feedback control law combined with the crane trajectory, which was planned by the detection of starting and ending points, was applied to achieve the goal of control. Vision-based control with online cable length estimation was introduced for other types of crane system, such as knuckle boom cranes, in Ref. 15 .

In the control of a gantry crane system, the goal is for the moving trolley to arrive at and come to rest at the desired position while varying the length of the cable to maintain it at a specified length. In addition, the swing angle of the lifting load is restrained within an allowable range. In this study, for an implemented prototype two-degree-of-freedom (2DOF) gantry crane system, a two-inputs-three-outputs VUFAPID control scheme is proposed to achieve the control goal. Traditional PID, fuzzy, and FAPID control schemes are also employed for comparison with the effectiveness of VUFAPID. The novelty of this study is the use of our experimental prototype to verify the position control of a 2DOF gantry crane system by using different control schemes.

This paper is organized as follows. The experimental prototype and dynamical model of a 2DOF gantry crane system are introduced in Sect. 2. The designs of four types of control scheme, including VUFAPID control, are outlined in Sect. 3. In Sect. 4, experimental results are given to illustrate the effectiveness of the VUFAPID control scheme. Finally, some concluding remarks are given in Sect. 5. 


\section{2DOF Gantry Crane System Model}

The experimental prototype of a 2DOF gantry crane, which is applied to analyze the tracking of the lifting trajectory and the swing motion of the lifting load, is shown in Fig. 1. The dynamical model of the 2DOF gantry crane is also shown in Fig. 2. The system consists of a trolley moving along a guided rail and a load hanging below the trolley from a controlled length of a lifting cable. The sensing system is combined with a vision system for detecting the position of the trolley and the length of the cable, and an angular sensor for measuring the swing angle of the load to sense the states of the 2DOF gantry crane.

The vision system includes a camera located in front of the 2DOF gantry crane and a hardware unit for connecting the camera for finding edges of objects and setting the coordinate system. The main operation of vision software is to discover edges by setting the contrast, filter width, and steepness. The contrast of an image is defined by the difference between the average pixel intensity before the edge and the average pixel intensity after the edge. The filter width specifies the number of pixels, and the steepness specifies the slope of the edge. The locations of the trolley and load are detected by the vision system, and the position of the trolley and the length of the cable are evaluated by a computational algorithm.

Two control problems must be simultaneously solved in the motion control of the system. The problem of trajectory tracking for accurate hoisting is to control the moving trolley to arrive at and come to rest at the desired position. The varying length of the cable is controlled to maintain it at a specified value. The problem of minimizing the swing of the lifting load involves controlling the swing angle of the load, which is the angle from the vertical line passing through the center of the trolley, to a value within a specified angular limit, for example, $10^{\circ}$.

Similarly to those in a previous work, ${ }^{(29)}$ the assumptions of the model of the gantry crane system are as follows.

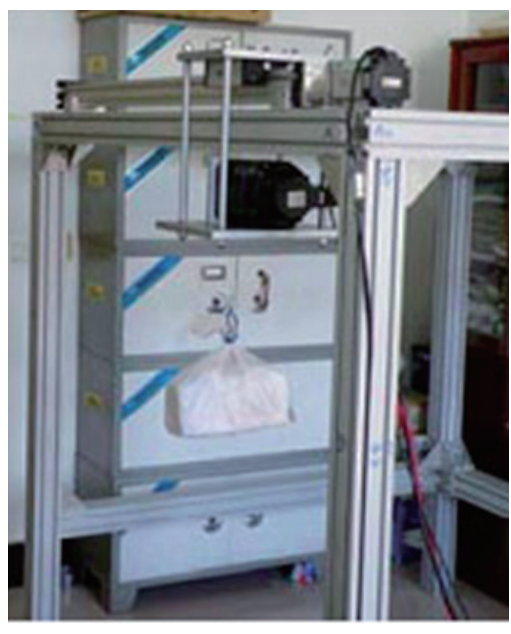

Fig. 1. (Color online) Experimental prototype of 2DOF gantry crane system.

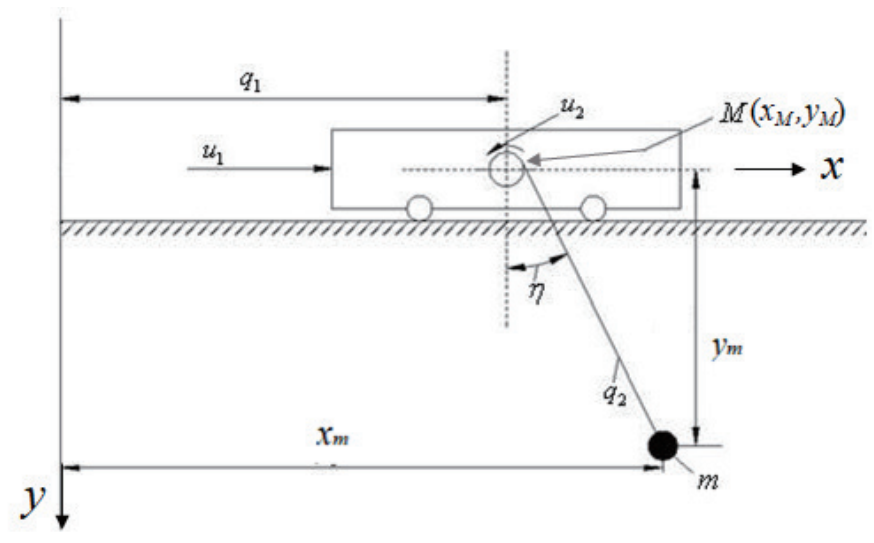

Fig. 2. Model of 2DOF gantry crane system. 
(1) The mass and the variation of the length of the cable are ignored.

(2) The friction between the trolley and the guide rail is ignored.

(3) The lifting load is regarded as a particle that moves only in the plane perpendicular to the horizontal plane.

(4) The effects of wind and air resistance are ignored.

(5) The nonlinearity of the transmission mechanism is neglected.

(6) The elastic deformation of the system is not taken into account.

The system parameters and variables of the 2DOF gantry crane model shown in Fig. 2 are listed in Table 1.

The dynamical equations of the 2DOF gantry crane model are derived using Lagrangian formalism by defining the generalized coordinates, such as the horizontal position of the trolley, $q_{1}$, the length of the cable, $q_{2}$, and the swing angle of the lifting load, $\eta \cdot{ }^{(29)}$ The following equations hold:

$$
\begin{gathered}
\ddot{q}_{1}=\frac{u_{1}-u_{2} \sin \eta}{M}, \\
\ddot{q}_{2}=\frac{M u_{2}-m u_{1} \sin \eta+m u_{2} \sin ^{2} \eta+M m g \cos \eta+M m q_{2} \dot{\eta}^{2}}{M m}, \\
\ddot{\eta}=\frac{-2 M \dot{q}_{2} \dot{\eta}-u_{1} \cos \eta+u_{2} \sin \eta \cos \eta-M g \sin \eta}{M q_{2}} .
\end{gathered}
$$

The error states are defined by $e_{1}(t)=q_{1, \text { reference }}-q_{1}(t), e_{2}(t)=q_{2, \text { reference }}-q_{2}(t)$, and $e_{3}(t)=-\eta(t)$, where $q_{1, \text { reference }}$ and $q_{2, \text { reference }}$ are the desired position of the trolley and the final length of the cable, respectively. The control goal is to design the appropriate control inputs, $u_{1}$ and $u_{2}$, such that $\lim _{t \rightarrow \infty} e_{i}(t) \rightarrow 0, i=1,2,3$.

Table 1

System parameters and variables of 2DOF gantry crane model.

\begin{tabular}{lrc}
\hline Symbol & Physical quantity & Value \\
\hline$M$ & Mass of trolley & Given \\
$m$ & Mass of load & Given \\
$h$ & Maximum lifting length of cable & Given \\
$q_{1}$ & Horizontal displacement of trolley & Variable \\
$\dot{q}_{1}$ & Horizontal velocity of trolley & Variable \\
$\ddot{q}_{1}$ & Horizontal acceleration of trolley & Variable \\
$\eta$ & Swing angle of lifting load & Variable \\
$\dot{\eta}$ & Swing angular velocity of lifting load & Variable \\
$\ddot{\eta}$ & Swing angular acceleration of lifting load & Variable \\
$q_{2}$ & Length of cable & Variable \\
$\dot{q}_{2}$ & Lifting velocity of cable & Variable \\
$\ddot{q}_{2}$ & Lifting acceleration of cable & Variable \\
$u_{1}$ & Horizontal driving force of trolley & Variable \\
$u_{2}$ & Lifting force of length of cable & Variable \\
\hline
\end{tabular}




\section{Design of Four Types of Control}

Two control inputs and three measured outputs are involved in the dynamical model of the 2DOF gantry crane system. As reported in this section, to achieve the desired effects of the 2DOF gantry crane system, a two-inputs-three-outputs VUFAPID control scheme is proposed to control the position of the trolley and the length of the cable. In addition, PID control, traditional fuzzy control, ${ }^{(30,31)}$ and FAPID control ${ }^{(20)}$ are also performed on the experimental gantry crane system for comparison with the effectiveness of VUFAPID.

(1) PID control scheme

Three PID controls are applied to control the variables $q_{1}, q_{2}$, and $\eta$ of the gantry crane system. Each PID control is expressed as

$$
u_{i}(t)=K_{P i} e_{i}(t)+K_{I i} \int e_{i}(t) d t+K_{D i} \frac{d e_{i}(t)}{d t}, i=1,2,3
$$

where $e_{1}(t)=q_{1, \text { reference }}-q_{1}(t), e_{2}(t)=q_{2, \text { reference }}-q_{2}(t)$, and $e_{3}(t)=-\eta(t)$. The tuned PID gains of the experimental gantry crane system are listed in Table 2.

(2) Traditional fuzzy control scheme

A schematic diagram of a traditional fuzzy controller is shown in Fig. 3. Its main parts include those for fuzzification, fuzzy inference, defuzzification, and input-output quantization. $^{(30)}$

Three traditional fuzzy controllers are provided to control the variables $q_{1}, q_{2}$, and $\eta$ of the gantry crane system. The membership functions are composed of seven fuzzy sets: positive big $(\mathrm{PB})$, positive medium (PM), positive small (PS), zero (ZO), negative small (NS), negative medium (NM), and negative big (NB). The membership functions are basically triangular, with

Table 2

Tuned PID gains of experimental system.

\begin{tabular}{lrll}
\hline & $K_{P i}$ & $K_{I i}$ & $K_{D i}$ \\
\hline$e_{1}(t)$ & 13.0 & 0.25 & 0.01 \\
$e_{2}(t)$ & 9.0 & 0.3 & 0.02 \\
$e_{3}(t)$ & 10.0 & 0.2 & 0.01 \\
\hline
\end{tabular}

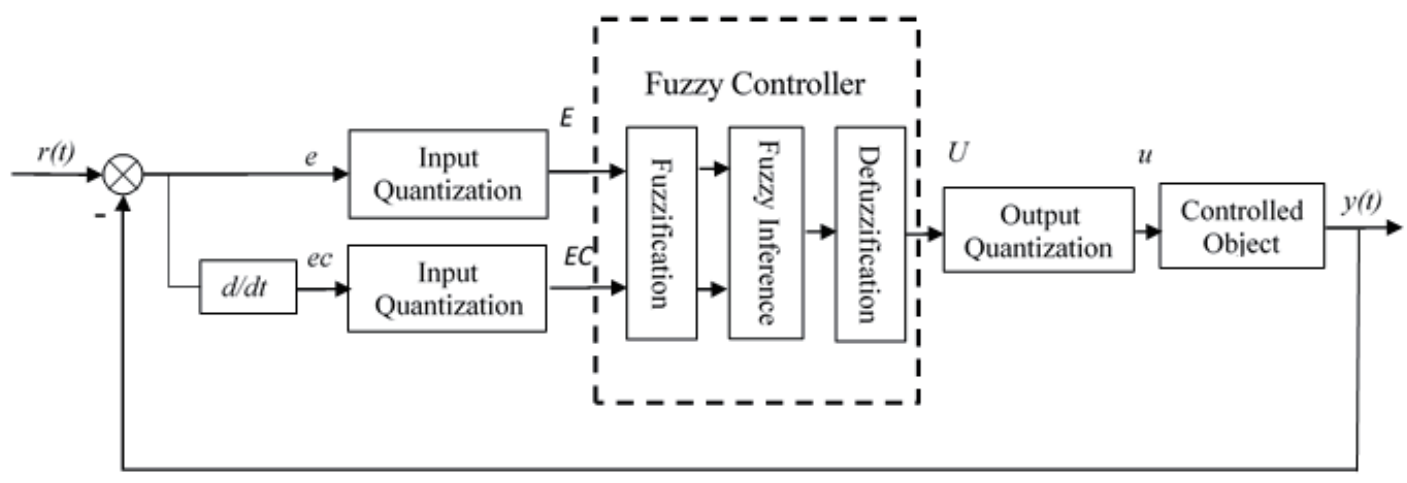

Fig. 3. Schematic diagram of traditional fuzzy controller. 
NB and PB using zmf and smf modes. ${ }^{(31)}$ The domain of the linguistic variables is $\{-3,-2,-1,0,1,2,3\}$ and the distributions of the membership functions are shown in Fig. 4.

The basic domain of the variation of the swing angle $\eta$ of the lifting load is $[-0.20,0.20] \mathrm{rad}$ and the domain of the swing angular velocity $\dot{\eta}$ is $[-0.05,0.05] \mathrm{rad} / \mathrm{s}$. The domain of the trolley displacement $q_{1}$ is $[-0.20,0.20] \mathrm{m}$ and the domain of the trolley velocity $\dot{q}_{1}$ is $[-0.30,0.30] \mathrm{m} / \mathrm{s}$. The domains of the cable length $q_{2}$ and the rate of change in cable length $\dot{q}_{2}$ are $[-0.25,0.25] \mathrm{m}$ and $[-0.50,0.50] \mathrm{m} / \mathrm{s}$, respectively. The domains of the trolley driving force $u_{1}$ and the cable lifting force $u_{2}$ are defined by $[-10,10] \mathrm{N}$ and $[-15,15] \mathrm{N}$, respectively. The fuzzy rules of $\left(q_{1}, \dot{q}_{1}, u_{1}\right)$ and $\left(q_{2}, \dot{q}_{2}, u_{2}\right)$ are listed in Table 3 and the fuzzy rules of $\left(\eta, \dot{\eta}, u_{1}\right)$ are listed in Table 4. The Mamdani method is used for the inference of the output control signals. The maximumminimum rules are employed for the operational composition of fuzzy rules, and defuzzification is performed to apply the centroid method to actual output control values with greater smoothness.

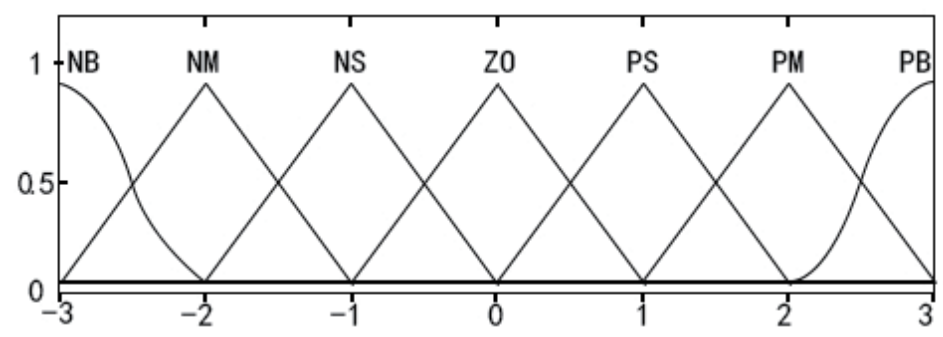

Fig. 4. Distributions of membership functions of linguistic variables.

Table 3

Fuzzy rules of $\left(q_{1}, \dot{q}_{1}, u_{1}\right)$ and $\left(q_{2}, \dot{q}_{2}, u_{2}\right)$.

\begin{tabular}{|c|c|c|c|c|c|c|c|c|}
\hline \multirow{2}{*}{$u_{1} / u_{2}$} & & \multicolumn{7}{|c|}{$q_{1} / q_{2}$} \\
\hline & & NM & NS & $\mathrm{ZO}$ & PS & PM & PB & \\
\hline \multirow{7}{*}{$\dot{q}_{1} / \dot{q}_{2}$} & NB & NB & NB & $\mathrm{ZO}$ & PM & PB & PB & PB \\
\hline & NM & $\mathrm{NM}$ & NM & $\mathrm{ZO}$ & PS & PB & PB & PB \\
\hline & NS & $\mathrm{NM}$ & NS & NS & PS & PM & PB & PB \\
\hline & $\mathrm{ZO}$ & NS & NS & NS & $\mathrm{ZO}$ & PM & PM & PB \\
\hline & PS & NB & NB & NM & NS & NS & PM & PM \\
\hline & PM & NB & NB & $\mathrm{NM}$ & $\mathrm{NM}$ & NS & PS & PM \\
\hline & PB & NB & NB & NB & NB & NB & PS & PS \\
\hline
\end{tabular}

Table 4

Fuzzy rules of $\left(\eta, \dot{\eta}, u_{1}\right)$.

\begin{tabular}{cllllllll}
\hline$u_{1}$ & & & & \multicolumn{1}{c}{$\eta$} \\
\cline { 3 - 8 } & & NM & NS & ZO & PS & PM & PB & \\
\hline \multirow{4}{*yyyyyyyy}{} & NB & NB & NB & NB & NM & NS & NM & NB \\
& NM & NB & NB & NS & NS & NS & NM & NB \\
& NS & NB & NM & NS & NS & NS & NM & NB \\
& ZO & NM & NS & NS & ZO & PS & PS & PM \\
& PS & PM & PS & PS & PS & PS & PM & PB \\
& PM & PM & PM & PM & PS & PS & PM & PB \\
& PB & PB & PB & PB & PM & PS & PM & PB \\
\hline
\end{tabular}


(3) FAPID control scheme

Three FAPID controllers are applied to control the variables $q_{1}, q_{2}$, and $\eta$ of the gantry crane system. For each FAPID controller, a two-inputs-three-outputs FAPID ${ }^{(20)}$ control scheme is introduced to control the position of the trolley and the length of the cable. The error and the rate of change in error $(e$ and $e c$ ) are the input variables of the fuzzy control scheme, and the outputs of the fuzzy control scheme are the gains of the PID, $K_{P}, K_{I}$, and $K_{D}$. The rules of fuzzy inference are based on the operator's experience and expert knowledge. The performance of the FAPID controllers is improved by the on-line self-tuning of the three gains, $K_{P}, K_{I}$, and $K_{D}$, of the PID. A schematic diagram of the control is shown in Fig. 5.

The domains of the input and output variables $e, e c, K_{P}, K_{I}$, and $K_{D}$ are $\{-3,-2,-1,0,1,2,3\}$. The membership functions of the input and output variables have the same shapes as those in Fig. 4. The fuzzy inference rules are expressed in Table 5. The inference, the operation and composition of rules, and the defuzzification are the same as those for the conventional fuzzy control scheme with the Mamdani, maximum-minimum, and centroid methods. ${ }^{(25,32)}$

(4) VUFAPID control scheme

Fuzzy PID control has many weak points, such as low control precision, the lack of PID integral factors, too many defined fuzzy rules, and the subjective selection of the membership functions. To overcome the above shortcomings of FAPID control, the concept of a variable universe domain is introduced into the FAPID control scheme.

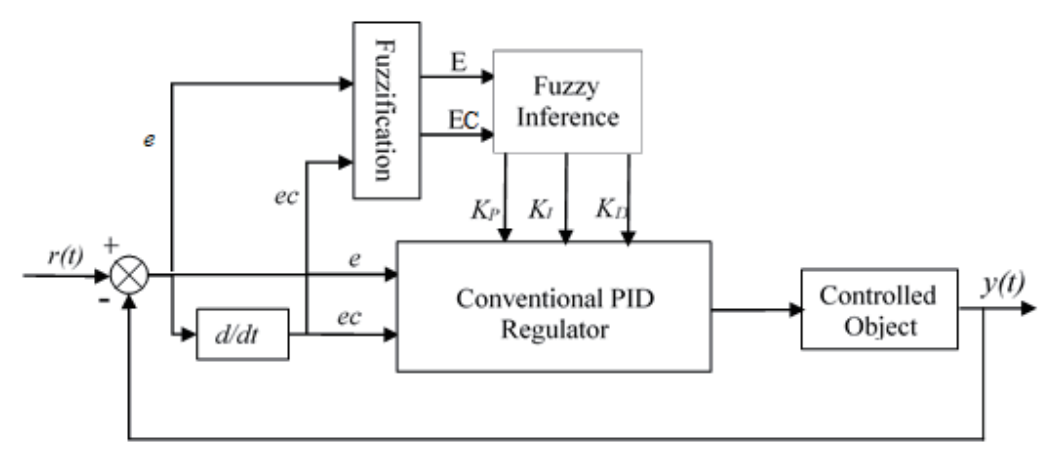

Fig. 5. Schematic diagram of the FAPID control scheme.

Table 5

Fuzzy rules of $e, e c, K_{P}, K_{I}$, and $K_{D}$.

\begin{tabular}{|c|c|c|c|c|c|c|c|c|}
\hline \multirow{2}{*}{\multicolumn{2}{|c|}{$K_{P} / K_{I} / K_{D}$}} & \multicolumn{7}{|c|}{$e$} \\
\hline & & NB & NM & NS & $\mathrm{ZO}$ & PS & PM & PB \\
\hline \multirow{7}{*}{$e c$} & NB & $\mathrm{PB} / \mathrm{NB} / \mathrm{PS}$ & $\mathrm{PB} / \mathrm{NB} / \mathrm{PS}$ & $\mathrm{PM} / \mathrm{NB} / \mathrm{ZO}$ & $\mathrm{PM} / \mathrm{NM} / \mathrm{ZO}$ & $\mathrm{PS} / \mathrm{NM} / \mathrm{ZO}$ & $\mathrm{ZO} / \mathrm{ZO} / \mathrm{PB}$ & $\mathrm{ZO} / \mathrm{ZO} / \mathrm{PB}$ \\
\hline & NM & $\mathrm{PB} / \mathrm{NB} / \mathrm{NS}$ & $\mathrm{PB} / \mathrm{NB} / \mathrm{NS}$ & $\mathrm{PM} / \mathrm{NM} / \mathrm{NS}$ & $\mathrm{PM} / \mathrm{NM} / \mathrm{NS}$ & $\mathrm{PS} / \mathrm{NS} / \mathrm{ZO}$ & $\mathrm{ZO} / \mathrm{ZO} / \mathrm{PS}$ & $\mathrm{ZO} / \mathrm{ZO} / \mathrm{PM}$ \\
\hline & NS & $\mathrm{PB} / \mathrm{NM} / \mathrm{NB}$ & $\mathrm{PB} / \mathrm{NM} / \mathrm{NB}$ & $\mathrm{PM} / \mathrm{NS} / \mathrm{NM}$ & $\mathrm{PS} / \mathrm{NS} / \mathrm{NS}$ & $\mathrm{NS} / \mathrm{ZO} / \mathrm{ZO}$ & NM/PS/PS & NM/PS/PM \\
\hline & $\mathrm{ZO}$ & $\mathrm{PM} / \mathrm{NM} / \mathrm{NB}$ & $\mathrm{PM} / \mathrm{NS} / \mathrm{NM}$ & $\mathrm{PM} / \mathrm{ZO} / \mathrm{NM}$ & $\mathrm{ZO} / \mathrm{ZO} / \mathrm{NS}$ & $\mathrm{NS} / \mathrm{PS} / \mathrm{ZO}$ & NB/PS/PS & NB/PM/PM \\
\hline & PS & $\mathrm{PM} / \mathrm{NS} / \mathrm{NB}$ & $\mathrm{PM} / \mathrm{NS} / \mathrm{NM}$ & $\mathrm{PS} / \mathrm{ZO} / \mathrm{NS}$ & NS/PS/NS & $\mathrm{NM} / \mathrm{PS} / \mathrm{ZO}$ & NB/PM/PS & NB/PM/PS \\
\hline & PM & $\mathrm{PS} / \mathrm{ZO} / \mathrm{NM}$ & $\mathrm{ZO} / \mathrm{ZO} / \mathrm{NS}$ & $\mathrm{ZO} / \mathrm{PS} / \mathrm{NS}$ & NM/PM/NS & NM/PM/ZO & NB/PB/PS & NB/PB/PS \\
\hline & PB & $\mathrm{ZO} / \mathrm{ZO} / \mathrm{PS}$ & $\mathrm{NS} / \mathrm{ZO} / \mathrm{ZO}$ & NS/PS/ZO & NM/PM/ZO & $\mathrm{NM} / \mathrm{PB} / \mathrm{ZO}$ & NB/PB/PB & $\mathrm{NB} / \mathrm{PB} / \mathrm{PB}$ \\
\hline
\end{tabular}


In Refs. 21 and 22, the idea of a variable universe domain that can contract when the error is decreasing or expand when the error is increasing was proposed. The effectiveness of fuzzy rules and the accuracy can be increased by domain contraction. The process of domain contraction is shown in Fig. 6. The key point of the variable universe domain involved in the FAPID control scheme is to let the basic domains of the input and output of the control system change with the control requirements by employing scaling factors.

The structure of the two-inputs-three-outputs VUFAPID control scheme, which combines the concept of a variable universe domain with the FAPID control scheme, is depicted in Fig. 7. The basic domains of the input and output can be varied with the control requirements. At the same time, the gains of PID control are tuned online and adapted by the variable universe fuzzy control scheme. Three VUFAPID controllers are utilized to control the variables $q_{1}, q_{2}$, and $\eta$ of the gantry crane system.

For each two-inputs-three-outputs VUFAPID control, the operations are described as follows. Let $\left[-e_{0}, e_{0}\right]$ be the basic domain of input variable $e,\left[-e c_{0}, e c_{0}\right]$ be the basic domain of input variable $e c,\left[-k_{p 0}, k_{p 0}\right]$ be the basic domain of output variable $K_{P},\left[-k_{i 0}, k_{i 0}\right]$ be the basic

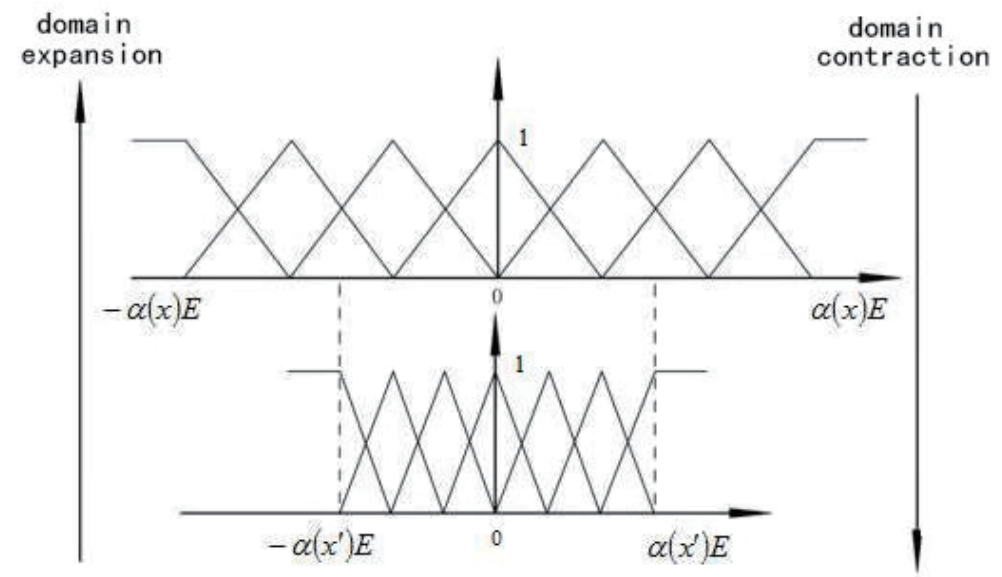

Fig. 6. Contraction and expansion of the variable universe domain.

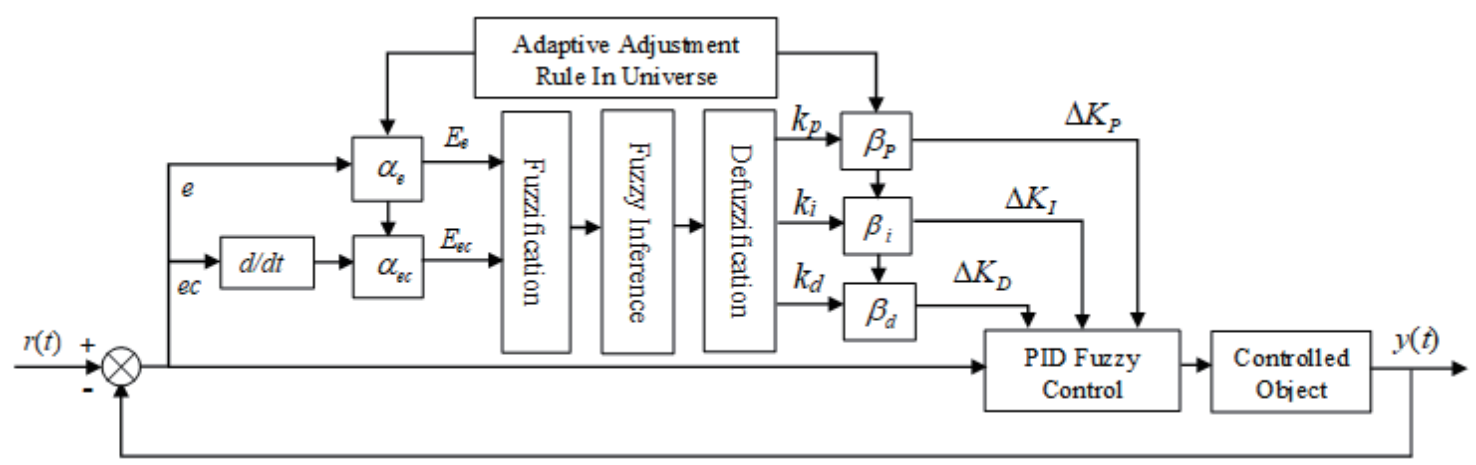

Fig. 7. Schematic diagram of VUFAPID control. 
domain of output variable $K_{I}$, and $\left[-k_{d 0}, k_{d 0}\right]$ be the basic domain of output variable $K_{D}$. For the two-inputs-three-outputs fuzzy inference system, it is assumed that $X_{P}=\left[-E_{p}, E_{p}\right], p=1,2$, is the basic domain of input variable $x_{p}$ and $Y_{q}=\left[-K_{q}, K_{q}\right], q=1,2,3$, is the basic domain of output variable $y_{q}$. The fuzzy partitions of $x_{p}$ and $y_{q}$ are given by $\left\{a_{p i}\right\}_{i}, p=1,2$ and $\left\{b_{q i}\right\}_{i}, q=1,2,3$ with $i=1,2, \ldots, 7$, respectively. We defined the matrices $A=\left[a_{1 i} a_{2 j}\right]_{7 \times 7}, B=\left[b_{q i}\right]_{3 \times 7}, i, j=1,2, \ldots$, 7. Then, for the given $7 \times 7$ fuzzy rules,

$$
\text { if } x_{1} \text { is } a_{1 i} \text { and } x_{2} \text { is } a_{2 j} \text {, then } y_{1} \text { is } b_{l}, y_{2} \text { is } b_{m} \text {, and } y_{3} \text { is } b_{n} \text {, }
$$

where the indexes are integers satisfying $1 \leq i, j, l, m, n \leq 7$. The fuzzy inference is derived as

$$
y_{q}=\sum A B^{T}=\sum_{i=1}^{7}\left[a_{1 i} a_{2 j}\right]\left[b_{j q}\right], q=1,2,3 .
$$

The concept of the variable universe is that the $X_{p}$ and $Y_{q}$ domains vary with and are selfadapted by the input and output variables $x_{p}$ and $y_{q}$, respectively. That is, the basic domains of the input and output variables can be expressed by $X_{p}\left(x_{p}\right)=\left[-\alpha\left(x_{p}\right) E_{p}, \alpha(x)_{p} E_{p}\right]$ and $Y_{q}\left(y_{q}\right)=$ $\left[-\beta\left(y_{q}\right) K_{q}, \beta\left(y_{q}\right) K_{q}\right]$, where $0<\alpha(x)$ and $\beta(y) \leq 1$ are the contraction-expansion factors of the input and output domains, respectively. In this study, the input contraction-expansion factors are defined by $\alpha(e)=1-0.6 \exp \left(-0.5 e^{2}\right)$ and $\alpha(e c)=1-0.6 \exp \left(-0.5(e c)^{2}\right)$, and the output contractionexpansion factors are defined by $\beta_{P}=\beta_{I}=2|e|, \beta_{I}=1 /(|e|+0.7)$. ${ }^{(33)}$

\section{Experimental Results}

In this section, the control effects of VUFAPID and the other three aforementioned control methods applied to the 2DOF gantry crane system are evaluated using the experimental system shown in Fig. 1. The system parameters are as follows. The masses of the trolley and load are 1 and $5 \mathrm{~kg}$, respectively. The initial trolley position is $q_{1}=0 \mathrm{~m}$ and the controlled target position is $q_{1}=1.0 \mathrm{~m}$. The length of the cable is controlled to decrease from $q_{2}=1.0$ to $0.5 \mathrm{~m}$. The experimental results of VUFAPID control, traditional PID control, traditional fuzzy control, and FAPID control are depicted in Figs. 8-11, respectively.

The trajectory tracking and anti-swing control for the above four control schemes are effective. The shortest settling time occurs for VUFAPID control. In the results for the position control of the trolley, overshoot occurs for traditional PID control and fuzzy control. By comparing the results in Figs. 9 and 10, traditional fuzzy control is found to have a slight advantage over traditional PID control for the 2DOF grant crane control system. By comparing the results in Figs. 8 and 11, the time required for the length of the cable to reach the designated length under FAPID control is considered to be larger than that under VUFAPID control. Regarding the swing angle of the load, the oscillation of the swing angle for VUFAPID control is the least frequent among the four control schemes. On the whole, VUFAPID control is superior to the other control schemes. The performance of the VUFAPID control scheme is acceptable when compared with the control performance in past studies. ${ }^{(12,13)}$ 


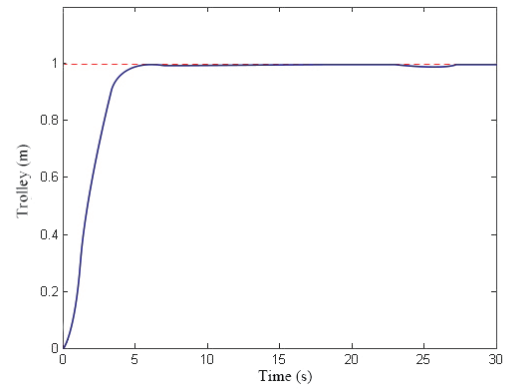

(a)

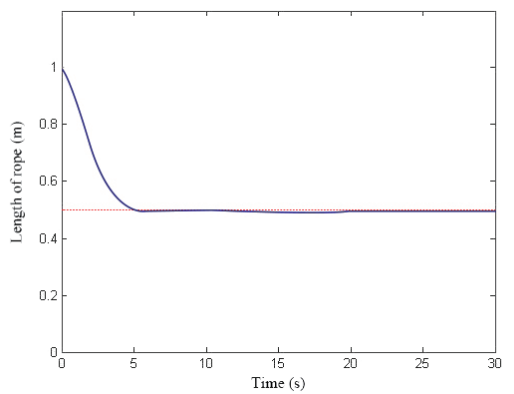

(b)

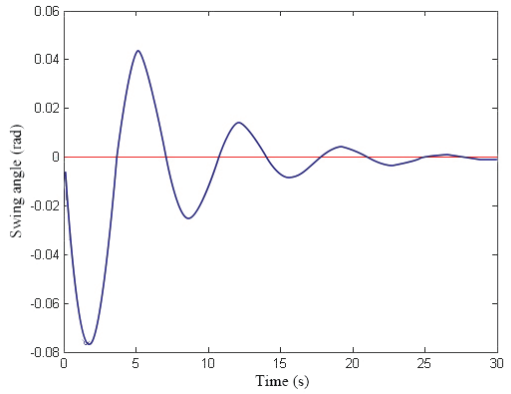

(c)

Fig. 8. (Color online) Experimental results of VUFAPID control. (a) Position of trolley. (b) Length of cable. (c) Swing angle of load.

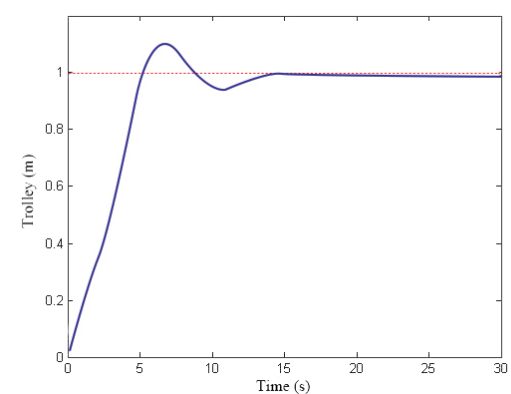

(a)

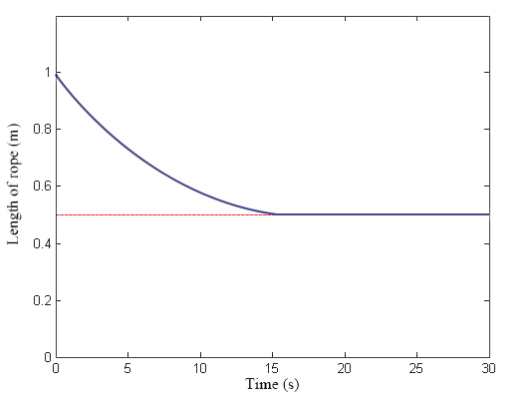

(b)

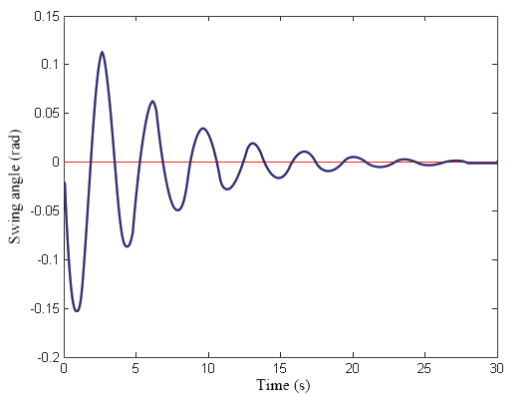

(c)

Fig. 9. (Color online) Experimental results of traditional PID control. (a) Position of trolley. (b) Length of cable. (c) Swing angle of load.

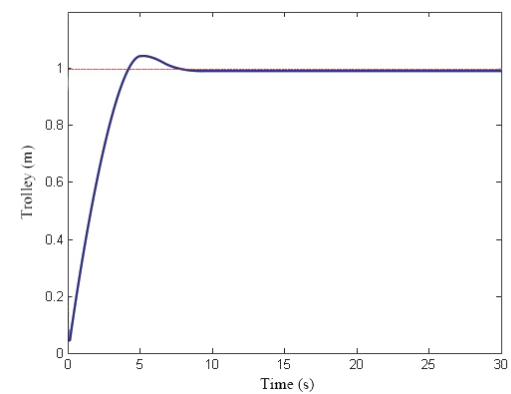

(a)

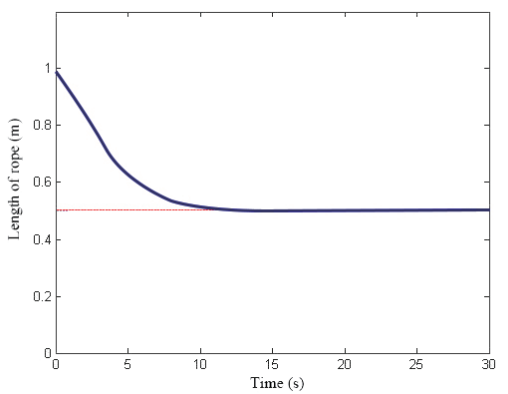

(b)

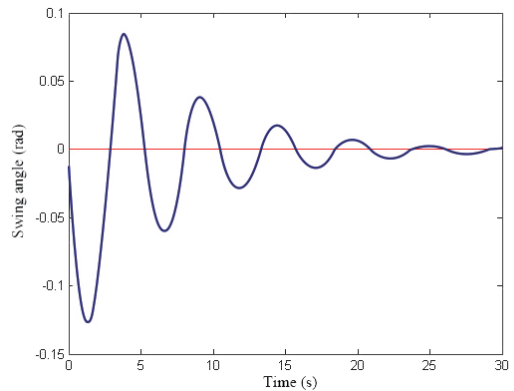

(c)

Fig. 10. (Color online) Experimental results of traditional fuzzy control. (a) Position of trolley. (b) Length of cable. (c) Swing angle of load.

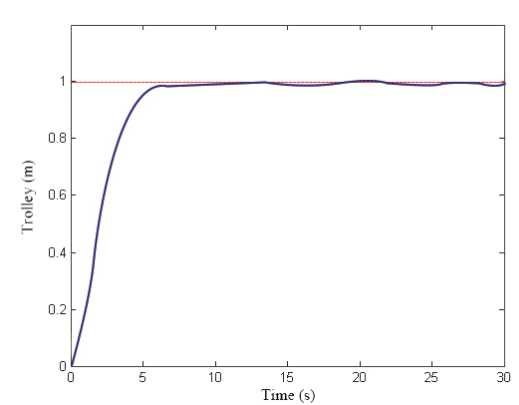

(a)

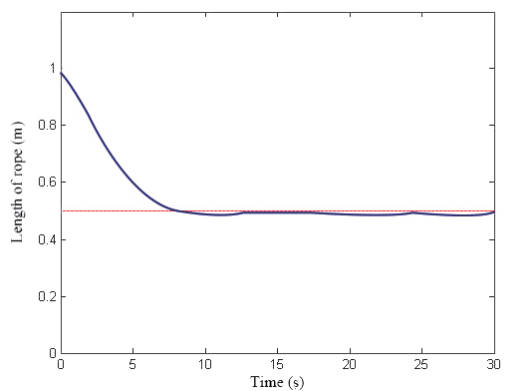

(b)

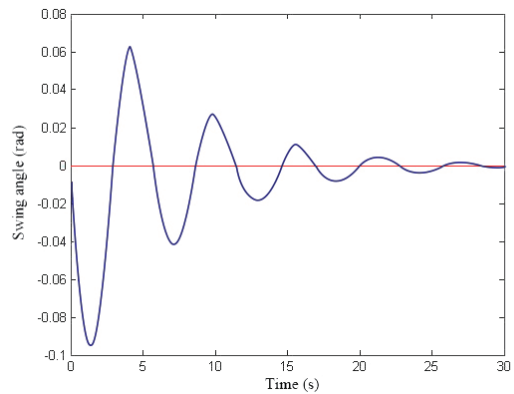

(c)

Fig. 11. (Color online) Experimental results of FAPID control. (a) Position of trolley. (b) Length of cable. (c) Swing angle of load. 


\section{Conclusion}

In the study, four types of control scheme, VUFAPID, FAPID, traditional PID, and fuzzy control schemes, are employed to control an experimental prototype of a 2DOF gantry crane system. The procedures of control design are described and the experimental results are given. According to the overall experimental results, the VUFAPID control scheme is superior to the other control schemes.

\section{Acknowledgments}

This work was carried out as part of the Intelligent Manufacturing Program coordinated by the Beautiful China Research Institute of Sanming University with financial support from the Natural Science Foundation Project of Fujian Science and Technology Department (2017J01777), the Scientific Research Department (16YG07), and the Operational Funding of the Advanced Talents for Scientific Research (19YG04) of Sanming University. The authors also acknowledge support from the School of Mechanical and Electrical Engineering of Sanming University.

\section{References}

1 O. Sawodnya, H. Aschemannb, and S. Lahres: Control Eng. Prac. 10 (2002) 1323. https://doi.org/10.1016/ S0967-0661(02)00097-7

2 O. Sawodny, J. Neupert, and E. Arnold: Fac. Mech. Eng. Trans. 37 (2009) 167.

3 S. B. Choi, S. S. Han, H. K. Kim, and C. C. Cheong: Mechatronics 9 (1999) 271. https://doi.org/10.1016/S09574158(98)00050-6

4 K. L. Sorensen, W. Singhose, and S. Dickerson: Control Eng. Pract. 15 (2007) 825. https://doi.org/10.1016/j. conengprac.2006.03.005

5 A. Okubanjol, O. Oyetola, and O. Adekomaya: ESKIȘEHİR Tech. Univ. J. Sci. Tech. A, Appl. Sci. Eng. 19 (2018) 1023. https://doi.org/10.18038/aubtda.420980

6 A. B. Rehiara: J. Inf. Commun. Tech. 1 (2011) 7.

7 Ü. Önen and A. Çakan: Inter. J. Eng. Comp. Sci. 6 (2017) 21612. https://doi.org/10.18535/ijecs/v6i6.12.

8 H. Butler, G. Honderd, and J. V. Amerongen: IEEE Control Syst. Mag. 11 (1991) 57. https://doi. org $/ 10.1109 / 37.103358$

9 H. Shi, G. Li, X. Bai, and J. Huang: Symmetry 11 (2019) 987. https://doi.org/10.3390/sym11080987

10 R. Mehra, S. Satpute, F. Kazi, and N. M. Singh: Proc. 21st Int. Symp. Mathematical Theory of Networks and Systems (2014) 1232.

11 N. T.-T. Vu, P. T. Thanh, P. X. Duong and N. D. Phuoc: Adaptive Robust Control Systems, Ed. A. T. Le (IntecOpen, 2018) Chap. 17. https://doi.org/10.5772/intechopen.72768

12 A. M. Singh, V. T. Hoang, and Q. P. Ha: Proc. 33rd Int. Symp. Automation and Robotics in Construction (ISARC 2016) 437. https://doi.org/0.22260/ISARC2016/0053

13 S. Frikha, M. Djemel, and N. Derbel: Int. J. Control Auto. Syst. 16 (2018) 559. https://doi.org/10.1007/s12555017-0070-x

14 S. U. Choi, J. H. Kim, J. W Lee Y. J. Lee, and K. S. Lee: Proc. IEEE Int. Symp. Industrial Electronics (IEEE ISIE 2001) 1896. https://doi.org/10.1109/ISIE.2001.932001

15 G. O. Tysse, A. Cibicik, and O. Egeland: IEEE/ASME Trans. Mecha. (2020). https://doi.org/10.1109/ TMECH.2020.3024637

16 L. Lee, C. Huang, S. Ku, C. Chang: Proc. 2013 Int. Conf. System Science and Engineering (ICSSE 2013$) 129$. https://doi.org/10.1109/ICSSE.2013.6614646.

17 L. A. Zadeh: Inf. Control 8 (1965) 338. https://doi.org/10.1016/S0019-9958(65)90241-X

18 J. J. Yan, K. K. Shyu, and J. S. Lin: Chaos Solitons Fractals 25 (2005) 347. https://doi.org/10.1016/j. chaos.2004.11.013

19 C. M. Lin and Y. J. Mon: IEEE Trans. Contr. Syst. Tech. 13 (2005) 593. https://doi.org/10.1109/ TCST.2004.843130 
20 W. Z. Qiao and M. Mizumoto: Fuzzy Sets Syst. 78 (1996) 23. https://doi.org/10.1016/0165-0114(95)00115-8

21 H. X. Li: Sci. in China Ser. E: Tech. Sci. 42 (1999) 10. https://doi.org/10.1007/bf02917053

22 S. Y. Oh and D. J. Park: Proc. IEEE Int. Conf. Systems, Man and Cybernetics (1995) 2628. https://doi. org/10.1109/ICSMC.1995.538179

23 H. X. Li, Z. H. Miao, and J. Y. Wang: Sci. China Ser. E: Tech. Sci. 45 (2002) 213. https://doi. org/10.1360/02ye9026

24 H. X. Li, Z. H. Miao, and E. S. Lee: Comp. Math. Appl. 44 (2002) 799. https://doi.org/10.1016/S08981221(02)00192-X

25 H. H. Lee: ASME J. Dyn. Syst. Meas. Control 120 (1998) 471. https://doi.org/10.1115/1.2801488

26 H. H. Lee and S. K. Cho: Proc. 2001 IEEE Int. Conf. Robotic and Automantion (2001) 2596.

27 M. J. Maghsoudi, Z. Mohamed, M. O Tokhi, A.R. Husain, and M. S. Z. Abidin: Trans. Inst. Meas. Control 39 (2017) 361. https://doi.org/10.1177/0142331215607615

28 H. M. Omar and A. H. Nayfeh: Shock Vib. 12 (2005) 73. https://doi.org/10.1155/2005/890127

29 A. Z. Al-Garni, K. A. F. Moustafa, and S. S. A. K. Javeed Nizami: Control Eng. Pract. 3 (1995) 1277. https:// doi.org/10.1016/0967-0661(95)00126-F

30 X. J. Ma, Z. Q. Sun, and Y. Y. He: IEEE Trans. Fuzzy Syst. 6 (1998) 41. https://doi.org/10.1109/91.811250

31 T. P. Hong and C. Y. Lee: Fuzzy Sets Syst. 84 (1996) 33. https://doi.org/10.1016/0165-0114(95)00305-3

32 M. C. Shih and M. A. Ma: Mechatronics 8 (1998) 241. https://doi.org/10.1016/S0957-4158(98)00005-1

33 Y. Zhu and J. P. Guo: J. Air Force Eng. Uni. (Natu. Sci. Ed., China) 6 (2005) 11. 